Article

\title{
Systematic Literature Review: Smart City Framework
}

\author{
Riki $^{1}$, Setyawan Widyarto ${ }^{2}$, Saliyah Kahar ${ }^{3}$ \\ ${ }^{1}$ Departement Information System, Universitas Buddhi Dharma, Banten, Indonesia \\ ${ }^{23}$ Departement Computing, Universiti Selangor, Malaysia
}

\begin{tabular}{l} 
SUBMISSION TRACK \\
\hline Recieved: Sep25, 2021 \\
Final Revision: Sep28, 2021 \\
Available Online: Sep29, 2021
\end{tabular}

KEYWORD

Smart city, Approach, Concept, Design,

Method, Model

CORRESPONDENCE

E-mail: riki@ubd.ac.ic

\begin{abstract}
A B S T R A C T
Smart cities are currently becoming the trend of large cities in the world and large cities in Indonesia. As the center of human civilization, cities cannot do without the problems of excess capacity and comfort. More and more people are migrating from the countryside to the cities, which brings new problems to the cities. Cities need to change to survive in the future. Strong indicators are needed to support cities, whether in terms of natural environment, society, communities, infrastructure, and education. In this article, we talk about a systematic literature evaluate of lookup associated to smart cities. The systematic literature evaluation is divided into three stages, introduction stage, demographic analysis stage and result analysis. The consequences disclose important symptoms of clever cities primarily based on the conclusions of previous research.
\end{abstract}

\section{INTRODUCTION}

Smart cities are currently becoming a fashion in primary cities in the world and most cities in Indonesia. At present, half of of the world's populace lives in cities, and this variety is anticipated to extend to $70 \%$ with the aid of 2050[1]. As the core of human civilization, cities cannot do besides the troubles of excess capability and comfort. More and extra human beings are migrating from rural to city areas, which brings new problems to cities.

A smart city is a city that video display units and integrates all key infrastructure conditions, such as roads, bridges, tunnels, trains/subway, airports, ports, communications, water, electricity, and even fundamental structures that can optimize resources and activities, water, electricity, and even fundamental structures that can optimize resources and activities. Implement safety prevention and monitoring to maximize the provision of services to its citizens. It shows that if the infrastructure is developed, the livability, workability and stability of the city can be achieved. For example, the progress of life provides the public with a better quality of life [2]. The Brundtland Commission's report has determined that citizens should have more opportunities to obtain a green, clean, safe, comfortable, and healthy lifestyle, and work ability means using resources to build a better jobs and sustainable economies to 
meet the needs of today's future generations. Meet your own needs in the future [3]. Therefore, the smart city factor can be divided into six categories: smart public transportation, economy, environment, people, life, and government[4].

1. Smart economy

Smart economy includes factors of economic competition, including innovation, entrepreneurship, trademarks, productivity, labor market flexibility, and market integration between countries[5]. Smart economic factors include innovation, entrepreneurship, economic image and trademarks, productivity, labor market flexibility, and ability to function. The field of work/smart economics conversation encompasses both local and global opportunity, productivity, and relationships [6]. There is an argument closer to Giffinger regarding the economics of wisdom, namely the emphasis on innovation and competition [7].

2. Smart environment

The smart environment is characterized by natural attractiveness (including climate, green space, etc.), pollution, resource management and environmental protection[5]. As explained in the description, the factors involved in a smart environment include natural attraction, pollution, environmental protection, and sustainable management of natural resources. At the same time, according to [6], the smart neighborhood is talking about smart development, natural resource management and the design of a robust city. It is also mentioned that smart surroundings are about sustainability or preserving the environment [7].

3. Smart People

A smart society can be described not only by its social feasibility or educational stage, but also by the quality of social interactions in people's lives and the degree of openness to the outside world[5]. The factors mentioned in the smart community include the feasibility stage, the attractiveness of lifelong learning, national and social diversity, flexibility, creativity, openness of opinion / views, and participation in community life. At the same time, according to [6], the field of conversation in a smart society includes integration, education, and creativity. Just like Cohen, [7]also mentions that creativity is an important aspect in an intelligent society.

4. Smart living

Smart life covers all aspects of life quality such as culture, health, safety, housing, travel, etc.[5]. These factors include cultural convenience, health status, personal safety, housing quality, educational convenience, tourist attraction and social cohesion. Smart living discusses culture and well-being, safety, and health [6]. Regarding the quality of life and culture as a consideration for smart living [7].

5. Smart Governance

Intelligent governance includes aspects such as political participation, civic services, and administrative functions [5]. Rely on the factors that exist in smart government, including participation in decision-making, public and social services, transparent government, and political strategies and opinions. [6] argues, smart government discusses online services, facilities and infrastructure, and open government. According to [7]smart government is seen in terms of empowerment and governance

6. Smart Transportation

Intelligent transportation is important in terms of local and international accessibility and the availability of modern and sustainable information. According to the above factors, the factors involved in intelligent transportation (such as local and international accessibility), the availability of information and communication technology infrastructure, and a sustainable, innovative, and safe transportation system. At the same time, according to [6], smart travel is about 
discussing transportation technology, multi-modal access, and efficient infrastructure[7]. Think of this as smart travel as it relates to traffic and travel.

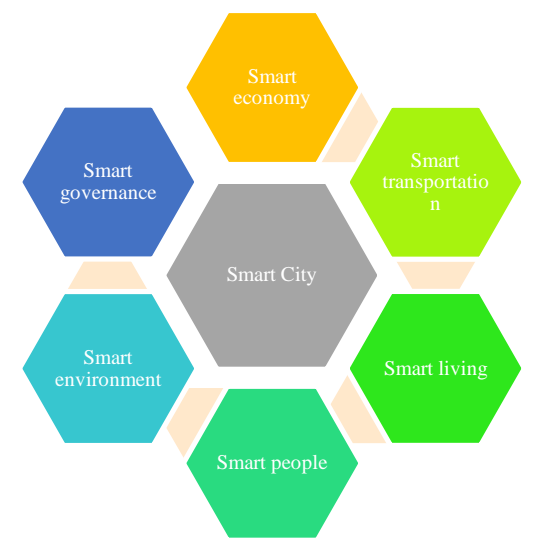

Figure 1 Smart City Factor

\section{LITERATURES REVIEW}

Today, $59 \%$ of the world's humans live in city regions[8], and $80 \%$ of the sector's human beings will stay in city regions in the future. It is expected that the area of cities will increase in the next few decades. The population growth has brought many difficulties to the airport, such as the transportation of talents, goods, labor, etc. Airports ought to find new methods to address the demanding situations of population boom and urbanization. Some technology-based research and methods have been developed to help create smart cities.

Investigated 31 fundamental cities round the arena and diagnosed many essential digital services in the cities, such as environment, electronic services, e-trade, digital security services and digital fitness services[9]. at the same time, they mentioned transportation, communication offerings, and getting to know for clever individuals who will improve the exceptional of lifestyles. Although they describe important aspects of smart cities, the background and concepts of smart cities are still complex. Talk about 3 importance standards related to smart cities, specifically primary theories, fashions and connotations[9]. In the basic theory, city halls, smart growth, living laboratories, and creative industries are considered indispensable for smart cities, and ICT is the preferred method in these basic areas. Regarding this research, in addition to the research published at the conference, it also relies on literature research and papers published by engineers, planners and construction engineers from 2016 to 2021.

The goal of a smart city is to provide people with a better lifestyle and a good city life, as well as basic public facilities[10]. The smart city concept requires sustainability, waste reduction, better social life, and good efficiency. With such requirements, transportation and communication are essential keys to constructing a smart city [11]. As more and more people move to districts or airports, there will be more infrastructure needs.

Look into smart towns and offer multidisciplinary analysis of actual advanced towns round the sector[12]. In their studies, they selected 63 papers from 33 city in North the USA, Asia, Europe, and South the United States. inside the same look at, European smart towns had been divided into six importance classes: economic system, human beings, authorities, lifestyles, surroundings, and transportation. In those six classes, major destiny problems and clever answers are being discussed. A robust economic gadget requires giant funding in new science and new areas. The growth of urban population requires more transportation. They face difficult problems in some of the applications they use. Since most information is private, it is difficult to find technical and specific details. As mentioned, populace growth has brought a broad range of challenges like air pollution, traffic 
congestion, waste management, safety, and healthcare.

Investigate the similarities and differences between clever cities and sustainable cities to locate a common framework[13]. Many definitions and explanations have been proposed in the literature, however most of them can be equated with accomplishing a balance between city region development and environmental protection in terms of income, employment, housing, fundamental services, social infrastructure, and transportation[14]. Smart cities are defined as the usage of the ultra-modern technologies to improve excellent of lifestyles in a variety of areas, such as infrastructure, transport systems, logistics and greenhouse fuel emissions.

The many definitions of the smart city thought, and its corresponding framework make it challenging for them to determine which well-known framework is excellent for the analysis. Therefore, the three standards are a framework that permits them to measure the depth, detail, and constraints of data within the framework of the smart city.

This evaluation depends on literature reviews, scientific sources, non-scientific sources, and websites. Based on their analysis, it is concluded that the essential factors of smart cities consist of education, culture, innovation, and Internet and Communication Technology (ICT), whilst sustainable cities center of attention on transportation, environment, water and waste administration [13]. Their investigation shows that safety and medical care are closely related to both. They concluded that sustainability should be part of the analytical intelligence of the city and be able to overcome all the challenges of the city.
Finally, they recommend sustainable use of smart cities rather than smart cities.

Explore the three areas of clever cities. The first location is smart metropolis development; the $2^{\text {nd }}$ focuses on the manner of urban construction, and the 0.33 focuses on land use patterns. They discussed the three core aspects of a clever city: technology, organization, and policy; they similarly believed that these factors have a brilliant influence on government, society, environment, economy, and infrastructure. They additionally mentioned the issues faced with the aid of cities around the world, such as air pollution, dirty water, erosion, and local weather change. In the end, they concluded that clever gaming groups have a beneficial influence on the surroundings and grant smart prevention solutions. The financial system will additionally advantage from land suitable for the development of clever cities.

Research on smart transportation science as section of clever cities and focus on predicting traffic congestion in peculiar situations such as incidents and extreme climate[15]. He overcomes this trouble via the usage of GPS to collect records from taxis to display unexpected situations. Recommend the Internet, technology, mobile Internet, cell smartphone purposes and cloud technological know-how to find massive traffic jams. This permits the driver to keep away from the area. This work has had a large influence on the industry by regulating traffic.

Research the risks and ideas of the framework of clever city construction with Chinese characteristics, and consider history statistics[15]. Regarding their ideas, they pointed out some essential dreams that clever cities have achieved, such as sustainable development, low priced housing, enhancing 
the satisfactory of existence of civilians, and financial growth. Risks can be determined based totally on budget constraints, aid scarcity, site visitors' congestion, air pollution, accidents, etc. Their conclusion from this study is that the use of science and ICT has made significant contributions to solving city troubles and keeping off risks. The Internet and cellular communications work collectively to collect records in the cloud and furnish the capability to analyze the records to entirely understand the problem. This research has made a sustainable contribution to our appreciation of clever cities and inspired local governments to help this section understand the gorgeous goals of smart cities.

The use of technology is the key to building a smart city. Technology is used to propose smart solutions to urban problems and make cities a livable place.

Define a smart city as investing in human and social capital, widely disseminating and promoting traditional smart public transportation and modern information and communication technology infrastructure, providing sustainable economic growth and high-quality living standards, and managing nature through participatory governance Resource city[16].

Nijkamp believes that a city uses participatory governance for wise natural resource management (SDA). This management is suitable for investing in human and social capital, modern transportation and communication infrastructure, sustainable economic development and high-quality life through information and communication technology. Priorities include natural resources, governance, society, transportation, economy, and quality of life. Smart cities also use information and communication technologies to support their urban services and focus on the importance of sustainable development by protecting natural resources and the environment.

There is also a definition of a smart city in [5], which states: "A city performs well in a forward-looking way in terms of economy, people, governance, mobility, environment, and life, based on the intelligent combination of endowments and activities. An independent and conscious citizen who decides on his own."

Giffinger believes that it is wise for a smart city to develop its city by looking to the future. The forward-looking urban development approach for smart cities considers issues such as contribution, selfassertion, independence, and awareness. Especially the issue of awareness. Only the communities, the private sector and the government are aware of the location of the city, that is, not only understand the city from within, but also understand the surrounding environment, can some potential be mobilized. Forward-looking urban development is carried out around six characteristics of economy, urban society, government, mobility, environment, and life. He believes that although some people continue to view smart cities narrowly as cities that make full use of information and communication technologies, Cohen himself views smart cities as a broad and comprehensive method to improve the efficiency and quality of urban operations. The lives of its citizens and the development of the local economy [17].

The concept of smart city is really talking about the use of modern technology in daily life. This is not only related to information and communication technology, but also related to modern transportation technology. In addition, all aspects of urban 
life are still related to the concept of smart cities, such as safety, greening, etc. Some people believe that although some people continue to view smart cities narrowly, they regard them as cities that make full use of smart cities. Information and communication technology, Cohen himself regards smart cities as a comprehensive approach to improve the efficiency of urban operations, the quality of life of citizens, and the development of the local economy[17].

The concept of smart city is really talking about the use of modern technology in daily life. This is not only related to information and communication technology, but also related to modern transportation technology. In addition, all aspects of urban life are still related to the concept of smart cities, such as safety, greenness, efficiency and sustainability, energy, etc. Therefore, efforts should be made to use information and communication technology to support resource management, improve community services, and improve the quality of life in urban communities, while still focusing on safety, reforestation, and sustainable development city

\section{METHODS}

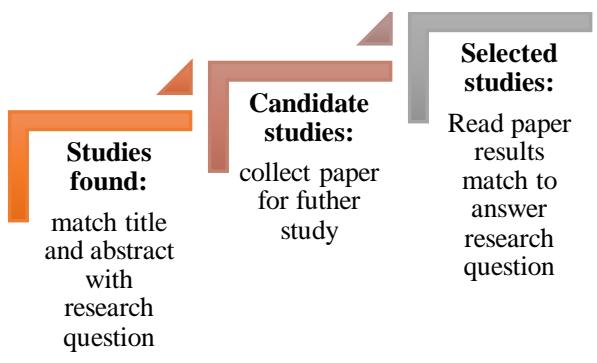

Figure 2. Inclusion Criteria

According to Ridley, "The first factor you should do is to habits a comprehensive literature review. The essential component is to explore how you will behavior research and gain knowledge and perception of present-day work and perspectives, so that your lookup can be placed on information Created on the academic map. An vital aspect of academic lookup is that it relates to the work of others[18].

The approach part describes the primary concepts of applying unique processes or methods to identify, select, and analyze the facts used to apprehend the lookup problem, so that readers can critically evaluate the standard validity and reliability of the research. The methodology phase of the lookup paper answers two most important questions: How is the records amassed or generated? And how is it analyzed? Writing ought to be direct and accurate, and usually use the past nerve-racking.

The reason of the literature evaluate is to hit upon the lookup project, determine its heritage or background, and supply insights into previous work [19]. The literature evaluation have to extract and synthesize the principal points, problems, findings, and lookup strategies that emerged from the imperative literature evaluate[18].

Systematic Literature Review is one method for conducting an in-depth literature review. There are three stages, namely the preliminary stage which includes the scope of the boundary, the determination of research questions, the search process which includes the selection of library sources and keywords, inclusion and exclusion criteria for sorting paper types and data extraction in the form of selected papers for further exploration [19].

The next step is to conduct research based on demographic data to determine 1) publishers, 2) most productive authors, 3) most productive institutions, 4) publishing trends, 5) trends and characteristics of the author's background, 6) Industry and country studied. The last part will discuss survey results and results in response to research questions.

\section{RESULT}

1. Quest level

The scope of this research is to summarize the potential indicators for 
implementing smart cities. The search process includes selected sources and keywords. The selected reference is Scopus. The keywords are concentrated in "smart city", "model" and "method", and possible synonyms are shown in Table 1.

Table 1. Synonyms of words

\begin{tabular}{|c|c|}
\hline Word & Synonym \\
\hline smart city & smart cities \\
\hline model & $\begin{array}{l}\text { design } \\
\text { concept }\end{array}$ \\
\hline method & $\begin{array}{l}\text { framework } \\
\text { approach }\end{array}$ \\
\hline
\end{tabular}

To have the possibility of a query based on the following keywords:

a. ("smart city" OR "smart cities")

b. ("model" OR "design") and ("model" OR "design" OR "concept") and

c. ("method" OR "framework") and ("method" OR "framework" OR "approach")

Exclusion criteria, as shown below, are required to eliminate studies that do not meet the requirements:
a. Published before 2016,
b. paper duplication,
c. Deep technical issues (apps, IoT),
d. Government regulatory issues

Data extraction started in July 2020 and examined 67 papers by keyword search from the List above against library sources (assisted by using the Publish and Perish application). After reading the abstracts, there were 54 candidate papers, and after reading them thoroughly and based on the exclusion criteria, 6 articles were selected for review.

2. Demographics and characteristic trends

2.1. Publishing channel

The publishing channel consists of many journals and conferences on the topic of smart transportation. Among them are Elsevier's journal and several conferences such as MDPI, with a total of 4 journals, and 2 conferences.

Table 2. Source of Publication Title

\begin{tabular}{|c|c|c|c|}
\hline No & Title & Year & Type \\
\hline 1 & $\begin{array}{l}\text { AWASN-Based Suburban } \\
\text { Dataset for Anomalous } \\
\text { Noise Event Detection on } \\
\text { Dynamic Road-Traffic } \\
\text { Noise Mapping [20] }\end{array}$ & 2019 & Journal \\
\hline 2 & $\begin{array}{l}\text { Gamification } \\
\text { educational strategy for } \\
\text { STEM learning: } \\
\text { DIGITgame project a } \\
\text { collaborative experience } \\
\text { between Italy and Turkey } \\
\text { high schools around the } \\
\text { Smart city concept [21] }\end{array}$ & 2019 & $\begin{array}{l}\text { Procee } \\
\text { ding }\end{array}$ \\
\hline 3 & $\begin{array}{l}\text { Data-driven flexibility } \\
\text { prediction in low voltage } \\
\text { power networks [22] }\end{array}$ & 2020 & Journal \\
\hline 4 & $\begin{array}{l}\text { Intelligent Transportation } \\
\text { System for Smart city } \\
\text { using VANET [23] }\end{array}$ & 2017 & $\begin{array}{l}\text { Procee } \\
\text { ding }\end{array}$ \\
\hline 5 & $\begin{array}{l}\text { An Approach to Frequency } \\
\text { Selectivity in an Urban } \\
\text { Environment by Means of } \\
\text { Multi-Path Acoustic } \\
\text { Channel Analysis [24] }\end{array}$ & 2019 & Journal \\
\hline 6 & $\begin{array}{l}\text { Evaluating spatial service } \\
\text { and layout efficiency of } \\
\text { municipal Wi-Fi facilities } \\
\text { for Smart City planning: A } \\
\text { case study of Wuhan city, } \\
\text { China [25] }\end{array}$ & 2018 & Journal \\
\hline
\end{tabular}

\subsection{List of Author}

Viewed from the perspective of the author of the analysis, there are 19 authors. No writer has consistently written about smart cities.

All these authors each wrote one paper, as shown in Table 4. List of authors, providing information that there are still many opportunities that can be used to maximize the function of smart transportation. 
Table 3. List of authors

\begin{tabular}{|c|c|c|c|c|c|}
\hline Author name & \# & $\%$ & Author name & \# & $\%$ \\
\hline $\begin{array}{l}\text { Rosa Ma } \\
\text { Alsina-Pagè }\end{array}$ & 2 & 10.5 & Ángel Paredes & 1 & 5.3 \\
\hline Ferran Orga & 1 & 5.3 & Pablo Arboleya & 1 & 5.3 \\
\hline Francesc Alías & 1 & 5.3 & $\begin{array}{l}\text { Chandrashekhar } \\
\text {.M. Raut }\end{array}$ & 1 & 5.3 \\
\hline $\begin{array}{ll}\text { Joan } & \text { Claudi } \\
\text { Socoró } & \end{array}$ & 1 & 5.3 & $\begin{array}{l}\text { Satish.R.Devan } \\
\text { e }\end{array}$ & 1 & 5.3 \\
\hline Laura Bonora & 1 & 5.3 & Pau Bergadà & 1 & 5.3 \\
\hline $\begin{array}{l}\text { Francesca } \\
\text { Martelli }\end{array}$ & 1 & 5.3 & $\mathrm{Xu}$ Tang & 1 & 5.3 \\
\hline $\begin{array}{l}\text { Valentina } \\
\text { Marchi }\end{array}$ & 1 & 5.3 & Ziyan Tan & 1 & 5.3 \\
\hline $\begin{array}{l}\text { Carolina } \\
\text { Vagnoli }\end{array}$ & 1 & 5.3 & Shiyuan $\mathrm{Hu}$ & 1 & 5.3 \\
\hline Javier Leiva & 1 & 5.3 & Hong Geng & 1 & 5.3 \\
\hline José A. Aguado & 1 & 5.3 & & & \\
\hline \multicolumn{3}{|l|}{ Total Author } & \multicolumn{3}{|c|}{19 of 6 titles } \\
\hline
\end{tabular}

2.3. Productive Institutions

Most of the source papers I use are published in indexed journals. This explains that the author has conducted an in-depth study for smart cities. The most prolific institution is the Grup de recerca en Tecnologies Mèdia, with two papers. Complete data can be seen in Table 5. List of Agencies.

There are differences in the number of documents in this table compared to Table 4. List of authors. This problem occurs because a paper can be written by more than one Author from different institutions.

Table 4. List of Institutions

\begin{tabular}{|l|l|r|r|}
\hline No & \multicolumn{1}{|c|}{$\begin{array}{c}\text { Institution } \\
\text { Number } \\
\text { of } \\
\text { Instituti } \\
\text { ons }\end{array}$} \\
\hline 1 & $\begin{array}{l}\text { Grup de recerca en } \\
\text { Tecnologies Mèdia }\end{array}$ & 3 & 33.3 \\
\hline 2 & Universitat Ramon Llull & 2 & 22.2 \\
\hline 3 & C/Quatre Camins & 2 & 22.2 \\
\hline 4 & $\begin{array}{l}\text { Institute } \\
\text { Biometeorology }\end{array}$ & 4 & 44.4 \\
\hline 5 & University of Málaga & 1 & 11.1 \\
\hline 6 & University of Oviedo & 1 & 11.1 \\
\hline 7 & Endesa, & 1 & 11.1 \\
\hline 8 & DMCE & 2 & 22.2 \\
\hline 9 & Wuhan University & 3 & 33.3 \\
\hline
\end{tabular}

2.4. Trend Publications

Although it is not very significant based on Figure 3. The year of publication, it is known that the interest of researchers in smart cities is increasing. It can be concluded that comfort and safety in using transportation is more concerned.

Frequency of papers published between 2016-2021. Most research related to smart transportation in 2019 (3 articles).

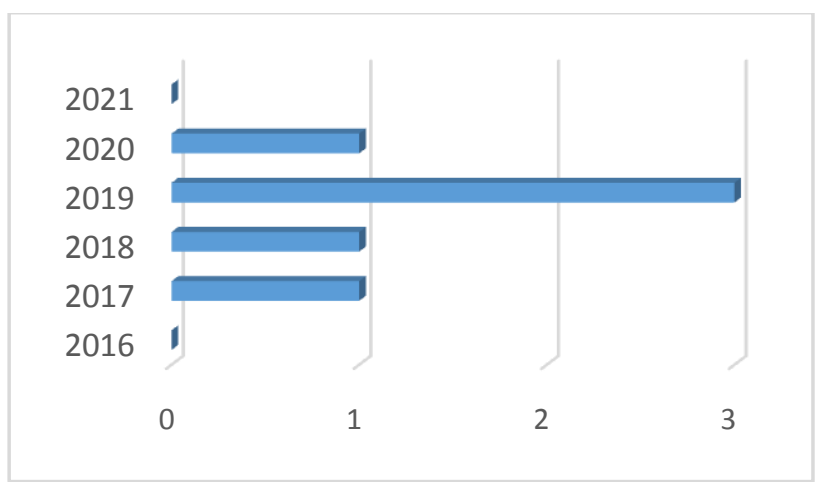

Figure 3. Year of Publication

\subsection{Authors Country}

Figure 4. Country of Author informs Country of Origin of Author. Most of the researchers came from Spain. This shows that the data is significant with the condition of the State, where the researcher focuses on Smart City, which follows the densely populated states.

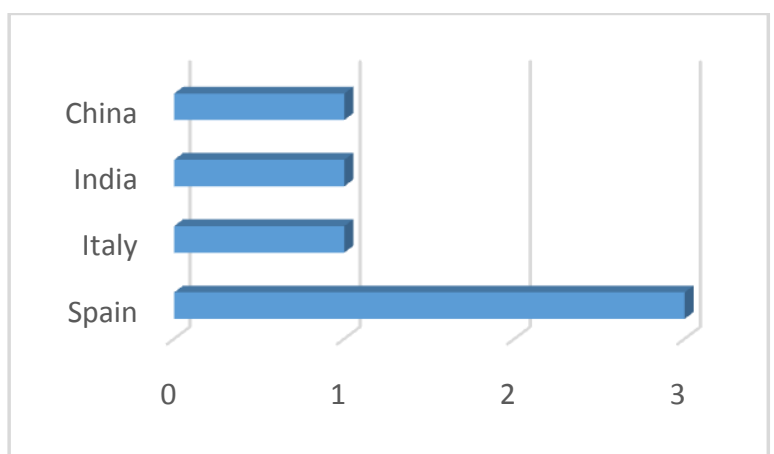

Figure 4. Authors Country

2.6. Author's scientific background

Table 5. Scientific background the author shows that most of the authors have a Technology background. This means that researchers have 
capabilities in their fields that help researchers to further explore the use of Smart City Technology, which can then be developed with other technologies.

Table 5.Author's scientific background

\begin{tabular}{|l|l|r|r|}
\hline No & Science background & Number & $\%$ \\
\hline 1 & Technology & 5 & 71.4 \\
\hline 2 & Biometeorology & 3 & 42.8 \\
\hline 3 & $\begin{array}{l}\text { Electrical } \\
\text { Engineering }\end{array}$ & 3 & 42.8 \\
\hline 4 & Engineering & 2 & 28.6 \\
\hline 6 & $\begin{array}{l}\text { Environmental } \\
\text { Sciences }\end{array}$ & 1 & \\
\hline 7 & $\begin{array}{l}\text { Geographic } \\
\text { Information System }\end{array}$ & 1 & 14.3 \\
\hline $\begin{array}{l}\text { Digital Mapping and } \\
\text { Land Information } \\
\text { Application } \\
\text { Engineering }\end{array}$ & 1 & 14.3 \\
\hline
\end{tabular}

\section{CONCLUSION}

The systematic literature under study can generate trends in the development of smart cities, especially in terms of indicators that are generally considered to be the main determinants of urban development. In the future, a systematic literature review can be conducted on cities of a certain scale, including large cities, small towns, and small cities. 


\section{REFERENCES}

[1] C. Colldahl, S. Frey, and J. E. Kelemen, "Smart Cities: Strategic Sustainable Development for an Urban World," Joseph E. Kelemen, 2013.

[2] K. Iqbal et al., "A smart camera for the surveillance of vehicles in intelligent transportation systems," Proc. - 2015 Int. Conf. Intell. Transp. Big Data Smart City, ICITBS 2015, vol. 6, no. 1, pp. 91-98, Jun. 2019, doi: 10.1007/s11042-015-3151-y.

[3] B. R. Keeble, "The Brundtland Report: 'Our Common Future," Med. War, vol. 4, no. 1, pp. 17-25, 1988, doi: 10.1080/07488008808408783.

[4] F. Purnomo, Meyliana, and H. Prabowo, "Smart city indicators: A systematic literature review," J. Telecommun. Electron. Comput. Eng., vol. 8, no. 3, pp. 161-164, 2016.

[5] R. Giffinger, C. Fertner, H. Kramar, and E. Meijers, "City-ranking of European mediumsized cities," Cent. Reg. Sci. Vienna UT, no. October, 2007.

[6] B. Cohen, "Boyd Cohen: 'The Smart City Wheel,"' The Smart City Wheel, 2015. .

[7] "IBM - United States," IBM builds a smarter planet, 2008. https://www.ibm.com/smarterplanet/us/en/ (accessed Dec. 04, 2020).

[8] Worldometers, "Population by Country (2020) - Worldometer," 2020. https://www.worldometers.info/world-population/population-by-country/ (accessed Jan. 31, 2020).

[9] L. Anthopoulos and P. Fitsilis, "Using Classification and Roadmapping techniques for Smart City viability's realization,” J. Appl. Entomol., vol. 11, no. 1, pp. 326-336, 2013, doi: 10.1111/j.1439-0418.2011.01655.x.

[10] D. R. Li, J. J. Cao, and Y. Yao, "Big data in smart cities," Sci. China Inf. Sci., vol. 58, no. 10, pp. 1-12, 2015, doi: 10.1007/s11432-015-5396-5.

[11] S. Roche, "Geographic Information Science I: Why does a smart city need to be spatially enabled?," Prog. Hum. Geogr., vol. 38, no. 5, pp. 703-711, Oct. 2014, doi: 10.1177/0309132513517365.

[12] S. Seravalli, Alessandro; Zubizarreta, Iker; Arrizabalaga, "Smart City Concept: What It Is and What It Should Be," J. Urban Plan. Dev., vol. 142, no. 1, pp. 1-9, 2016, doi: 10.1061/(ASCE)UP.

[13] H. Ahvenniemi, A. Huovila, I. Pinto-Seppä, and M. Airaksinen, "What are the differences between sustainable and smart cities?," Cities, vol. 60, pp. 234-245, Feb. 2017, doi: 10.1016/j.cities.2016.09.009.

[14] R. B. Hiremath, P. Balachandra, B. Kumar, S. S. Bansode, and J. Murali, "Indicator-based urban sustainability-A review," Energy Sustain. Dev., vol. 17, no. 6, pp. 555-563, 2013, doi: 10.1016/j.esd.2013.08.004.

[15] H. Wang, "Sensing information modelling for smart city," Proc. - 2015 IEEE Int. Conf. Smart City, SmartCity 2015, Held Jointly with 8th IEEE Int. Conf. Soc. Comput. Networking, Soc. 2015, 5th IEEE Int. Conf. Sustain. Comput. Communic, pp. 40-45, 2015, doi: 10.1109/SmartCity.2015.44.

[16] A. Caragliu, C. D. E. L. Bo, and P. Nijkamp, "Paper Nijkamp et al Smart cities in Europe 2009," CERS 2009, 7-9 Oct. Kosice, Slovak Republic., pp. 45-59, 2009, doi: 10.1080/10630732.2011.601117.

[17] B. Cohen, "Boyd Cohen | Fast Company," Fast Company, 2012. https://www.fastcompany.com/user/boyd-cohen (accessed Dec. 04, 2020).

[18] L. Blaxter, C. Hughes, and M. Tight, How to Research, 3rd ed. Open University Press, 2012.

[19] R. T. Sataloff, M. M. Johns, and K. M. Kost, The Literature Review: A Step-by-Step Guide for Students, 2nd ed. London: SAGE Publications Ltd, 2012. 
[20] R. M. Alsina-Pagès, F. Orga, F. Alías, and J. C. Socoró, "A WASN-based suburban dataset for anomalous noise event detection on dynamic road-traffic noise mapping," Sensors (Switzerland), vol. 19, no. 11, 2019, doi: 10.3390/s19112480.

[21] L. Bonora, F. Martelli, V. Marchi, and C. Vagnoli, "Gamification as educational strategy for STEM learning: DIGITgame project a collaborative experience between Italy and Turkey high schools around the Smartcity concept.," IMSCI 2019 - 13th Int. MultiConference Soc. Cybern. Informatics, Proc., vol. 2, no. Imsci, pp. 122-127, 2019.

[22] J. Leiva, J. A. Aguado, Á. Paredes, and P. Arboleya, "Data-driven flexibility prediction in low voltage power networks," Int. J. Electr. Power Energy Syst., vol. 123, no. February, p. 106242, 2020, doi: 10.1016/j.ijepes.2020.106242.

[23] C. M. Raut and S. R. Devane, "Intelligent transportation system for smartcity using VANET," Proc. 2017 IEEE Int. Conf. Commun. Signal Process. ICCSP 2017, vol. 2018Janua, pp. 1602-1605, 2018, doi: 10.1109/ICCSP.2017.8286659.

[24] P. Bergad and R. M. Alsina-Pagès, "An approach to frequency selectivity in an urban environment by means of multi-path acoustic channel analysis," Sensors (Switzerland), vol. 19, no. 12, 2019, doi: 10.3390/s19122793.

[25] X. Tang, Z. Tan, S. Hu, and H. Geng, "Evaluating spatial service and layout efficiency of municipal Wi-Fi facilities for SmartCity planning: A case study of Wuhan city, China," Socioecon. Plann. Sci., vol. 65, pp. 101-110, 2019, doi: 10.1016/j.seps.2018.03.001.

\section{BIOGRAPHY}

Riki, a lecturer in the Department of Information Systems at Universitas Buddhi Dharma since 2008. Graduated from Universitas Raharja (2006) and STMIK Eresha (2010). Currently studying for a doctoral program at the Universiti Selangor.

Setyawan Widyarto, He received first degree from IPB Bogor in 1986 and M.Sc. degrees in Manufacturing System Engineering and Management from University of Bradford (UK) under Chevening Awards (British Council) in 1998. In 2008 he finished his Ph.D. degree in Computer Science from University Teknologi Malaysia and joined University Selangor (Unisel). Since 2012, he has been an Associate Professor with the Computing Department, Unisel Bestari Jaya, Kuala Selangor. He has more than 35 years working experience in industries and academics. He is an editor member and chief editor some journals. He ever held some Deanships in Computing Faculty, Centre for Foundation and General Studies and Centre for Graduate Studies.

Saliyah Kahar, currently works at the Faculty of Communication, Visual Art and Computing, UNISEL | Universiti Selangor. Saliyah does research in Algorithms, Computer Communications (Networks) and Educational Technology. Their current project is 'software quality model'. 